\section{Homicide and mental illness in New Zealand,} 1970-2000

\author{
ALEXANDER I. F. SIMPSON, BRIAN MCKENNA, ANDREW MOSKOWITZ, \\ JEREMY SKIPWORTH and JUSTIN BARRY-WALSH
}

\author{
Background Homicides by mentally ill \\ persons have led to political concerns \\ about deinstitutionalisation.
}

\begin{abstract}
Aims To provide accurate information about the contribution of mental illness to homicide rates.
\end{abstract}

Method Retrospective study of homicide in New Zealand from 1970 to 2000 , using data from government sources. 'Mentally abnormal homicide' perpetrators were defined as those found unfit to stand trial, not guilty by reason of insanity, convicted and sentenced to psychiatric committal, or convicted of infanticide. Group and time trends were analysed.

Results Mentallyabnormal homicides constituted $8.7 \%$ of the 1498 homicides.

The annual rate of such homicides was 1.3 per million population, static over the period. Total homicides increased by over $6 \%$ per year from 1970 to 1990 , then declined from 1990 to 2000 . The percentage of all homicides committed by the mentally abnormal group fell from $19.5 \%$ in 1970 to $5.0 \%$ in 2000 . Ten per cent of perpetrators had been admitted to hospital during the month before the offence; $28.6 \%$ had had no prior contact with mental health services. Victims were most commonly known to the perpetrator (74\%).

Conclusions Deinstitutionalisation appears not to be associated with an increased risk of homicide by people who are mentally ill.

Declaration of interest None. Funding detailed in Acknowledgements.
In New Zealand - as elsewhere - homicides by people with a serious mental illness are given wide media coverage, stigmatising and promoting societal fear of people with such illnesses. However, no increase in homicides by people with mental illness following deinstitutionalisation was found by Gottlieb et al (1987) in Denmark or by Taylor \& Gunn (1999) in the UK, and only a small increase was found by Erb et al (2001) in Germany. Australian data found that rising numbers of convictions for violence of people with schizophrenia paralleled rising levels of general societal violence (Mullen et al, 2000; Wallace et al, 2004). Coid (1983) found that the rates of mentally abnormal homicide were relatively uniform between countries - ranging from 0.8 to 2.2 per million annually. Perpetrators may be unknown to mental health services (Leong \& Silva, 1995; Shaw et al, 1999) and victims are more often family members and less often strangers, when compared with the victims of mentally normal perpetrators (Gottlieb et al, 1987; Shaw et al, 1999).

We aimed in this study to determine the annual rate of homicide committed by people with serious mental illness, to determine whether this rate changed in parallel with deinstitutionalisation or with total homicide rates, to describe the characteristics of homicide perpetrators and victims and to determine mental health service contact by the perpetrators prior to the offence.

Deinstitutionalisation in New Zealand commenced in the 1960s. In 1970 there were 350 psychiatric hospital beds per 100000 population, falling steadily to 38 per 100000 in 1998, replaced by a substantial growth in community-based services from the early 1990s.

\section{METHOD}

We defined homicide as events of culpable homicide involving murder, manslaughter or infanticide as defined in New Zealand legislation. 'Mentally normal homicide' and 'mentally abnormal homicide' were defined by legal criteria. Mentally normal homicides were those resulting in convictions of murder and manslaughter and included murder suicide. Murder suicide was not included in the mentally abnormal group as there had been no legal determination of a nexus between mental abnormality and the homicide.

People committing homicide who also have a serious mental illness have four mental health dispositions through the courts: unfit to stand trial; not guilty by reason of insanity; convicted and sentenced to psychiatric committal; and convicted of infanticide. These four groups are collectively referred to as 'mentally abnormal homicide offenders'. Legislation in relation to the legal test for insanity, fitness to stand trial and infanticide did not change significantly over the period of this study. Insanity in New Zealand law is broadly based on the McNaughton rules. There is no general plea of diminished responsibility in New Zealand law.

There may be other offenders who also have a diagnosis of a serious mental illness but are found legally responsible for their offence. These offenders were not included in the mentally abnormal homicide group, as no relationship was established by the courts between the mental illness and the offence.

\section{Study design}

The data sources used were secondary databases in a variety of government agencies. These sources, which varied in quality over time, were:

(a) the Homicide Monitoring Database of the New Zealand Police, which is a detailed schedule of all homicide events since 1988 with information regarding the circumstances surrounding the event, the victim(s) and the suspect(s) charged with the offence;

(b) the Law Enforcement System, which is a national database of criminal prosecutions dating from 1979. Information includes standard demographic data, the date of the offence, and the outcome of the court process;

(c) the files of all persons who receive a mental health service disposition after a homicide, which are held by the Ministry of Health; 
(d) the New Zealand Parole Board database of persons convicted of murder from 1970;

(e) the New Zealand Health Information Service database, which records admission and discharge details of hospitalisation and diagnosis from 1988;

(f) the Coroner's Court files of deaths by homicide or suicide, which was searched using the names of murder suicide perpetrators obtained from other databases;

(g) the New Zealand Herald index of homicide cases, which was searched for names of perpetrators and victims for the years 1970-1990;

(h) the New Zealand Official Yearbook of annual statistics, published by Statistics New Zealand (http://www.stats.govt.nz). Annual aggregate data for manslaughter and infanticide were obtained to cover the years 1970-1979, when other data sources were not developed.

New Zealand has a crime clearance rate for homicide that has averaged $74 \%$ for the past 8 years (Office of the Police Commissioner, 2003), which is relatively high in international terms, although not as good as the $97 \%$ rate in Finland (Eronen et al, 1996).

\section{Data-set coverage and combination}

Because no single source was comprehensive, data sources were cross-referenced to maximise data completeness and accuracy. Murder cases were defined by the Parole Board data. Individual manslaughter and infanticide cases were accessed through the Law Enforcement System database from 1979, but aggregate data from the Yearbook were used for the period 1970-1979. Mental health cases were identified in the Ministry of Health data-set. In order to maintain consistency in diagnostic categorisation over the study period, the Ministry files were reviewed by a psychiatrist (J.B.-W.), who recorded diagnoses using DSM-IV criteria (American Psychiatric Association, 1994). Mental health contacts were obtained from the New Zealand Health Information Service from 1988 onwards, and victim types from the Homicide Monitoring Database from 1988. Murder suicide cases were identified in the New Zealand Herald index until 1988, and the Homicide Monitoring Database from 1988. Data were supplemented from coroners' records. A full description of the data sources is contained in our report to the Health Research Council (Simpson et al, 2003).

Studies of this type are limited by the fact that original data were gathered by non-researchers for a purpose other than clinical research. Although we were likely to detect most major psychotic illness, we have probably missed many cases of personality disorder, substance misuse and depressive disorders. Specific data-sets have particular limitations as well. Ethnicity, along with other socio-demographic variables, was poorly and incompletely recorded. Although the more recent versions of the data-sets were more complete and made possible more detailed analysis of the years following 1988, examination of time trends required a longer interval, which necessitated using earlier, less complete data-sets.

Data were entered into the Statistical Package for the Social Sciences, version II (SPSS, 2002) for analysis. Results are presented as raw frequencies. The percentage of mentally abnormal homicide was presented in annual groupings. The analysis of the change in proportion of such homicides over time used a Poisson regression model. Annual rates of change in homicide and the proportion of mentally abnormal homicide can be calculated from this analysis.

Ethical approval for this multicentre study was granted by the Auckland Ethics Committee and permission for access to specific data-sets was gained by research agreements with the Director of Mental Health, the Commissioner of Police and the Ministry of Justice.

\section{RESULTS}

The total number of people committing homicide in the study period was 1498 Of these, mentally abnormal homicide perpetrators numbered 130 (8.7\% of all homicides), of whom 83 were found not guilty by reason of insanity $(5.5 \%$ of all homicides), 23 were convicted of infanticide $(1.5 \%), 23$ were unfit to stand trial $(1.5 \%)$ and 1 was convicted and committed to psychiatric hospital $(0.1 \%)$. Of the 1368 cases of mentally normal homicide $(91.3 \%$ of all homicides), 714 perpetrators were convicted of manslaughter $(47.7 \%$ of all homicides), 569 of murder (38.0\%), 81 of murder suicide $(5.4 \%)$ and 4 were discharged without conviction $(0.3 \%)$.

We examined the number of perpetrators of homicides per million population per year in the period 1970-2000 (Fig. 1). A piece-wise Poisson regression was undertaken using the arbitrarily chosen year of 1990 as the change point. For this regression the pre-1990 line shows a total homicide increase of $6.3 \%$ per year $195 \%$ CI 5.1 to 7.5 ). After 1990 the line shows a change to a decrease of $2.1 \%$ per year (95\% CI -3.7 to -0.5$)$. This change was gradual over the years 1987 to 1992 . A Poisson regression of the incidence of mentally abnormal homicide over the period 1970-2000 was also undertaken, but owing to the variability in the number of cases each year of between 0 and 9 , no time trend was detected. The number of perpetrators of mentally abnormal homicide is taken as constant at $\mathbf{1 . 3}$ per million population per year (95\% CI 1.0 to 1.6 ).

As a percentage of total homicide, mentally abnormal homicide has reduced from $19.5 \%$ in the first 5 years of the study to an average of $5.0 \%$ in the last 5 years of the study (Fig. 2). A Poisson model was fitted to the percentage of mentally abnormal homicide, finding a decrease in proportion of 0.042 mentally abnormal perpetrators per year. As a percentage this is a decline of $4.2 \%$ per year $(95 \%$ CI 1.7 to 6.6).

\section{Characteristics of homicide perpetrators}

Demographic data were available for 126 perpetrators of mentally abnormal homicides (in 4 early cases of infanticide the perpetrator could not be traced). Of these, $86(68 \%)$ were male and $40(32 \%)$ female. Their ages ranged from 14 years to 71 years, with a mean age of 33.6 years (s.d.=13.2). Diagnostically, 55 had a primary schizophrenic disorder, 19 another psychotic disorder, 13 major depressive disorder (primarily from the infanticide group) and 5 a bipolar disorder. Alcohol or substance misuse diagnoses were made in 10 cases. Nine people had organic brain disorders, 11 a primary or secondary personality disorder and 9 intellectual disability. As comorbid conditions were not systematically recorded, the personality and substance misuse problems are almost certainly underestimates of the true prevalence. 
Table 1 compares the socio-demographic variables of the perpetrators of mentally normal and mentally abnormal homicides for 1979-2000. This period was examined because limited demographic detail was available about mentally normal offenders prior to establishment of the Law Enforcement System database in 1979. The mentally abnormal homicide group were significantly more likely to be female (33\% v. 9\%, Pearson $\chi^{2}=52.2$, d.f. $=1$, $P<0.001)$. A fifth of the mentally normal offenders whose age range was known were aged 14-19 years: this accounts for the significant difference in age between the two samples (Pearson $\chi^{2}=29.9$, d.f. $=5$, $P<0.001)$. There was no significant difference in the ethnic compositions of the two groups.

Thirty-seven $(29 \%)$ of the 126 perpetrators of mentally abnormal homicides during the period 1970-2000 had had no prior psychiatric hospital admission, compared with $65(52 \%)$ who had had a prior admission; no information was available for $27(21 \%)$. Of those with a prior psychiatric admission, $13(10 \%)$ had been admitted within the previous month and $25(20 \%)$ within the previous year. Most people who had been admitted had only been admitted on one or two occasions in the previous 5 years.

\section{Characteristics of the victims of homicide}

Information about the victims on the Homicide Monitoring Database was available only for the years 1988 to 2000, and even for this period there was a large amount of missing data, which hampered further analysis.

Relationship to the offender could be assigned for most victims of mentally abnormal homicide: family members or partners of the perpetrators were the victims on 65 occasions ( $74 \%$ of mentally abnormal homicide victims); strangers were identified on 2 occasions ( $3 \%$ of victims). The victims of mentally normal homicide were strangers on 82 occasions $(9 \%$ of known victims of mentally normal homicide). Put differently, of the 84 victims who were killed by strangers during the period 1988-2000, only 2 were killed by people who were mentally ill.

\section{DISCUSSION}

We found a rate of 1.3 mentally abnormal homicides per million population per year

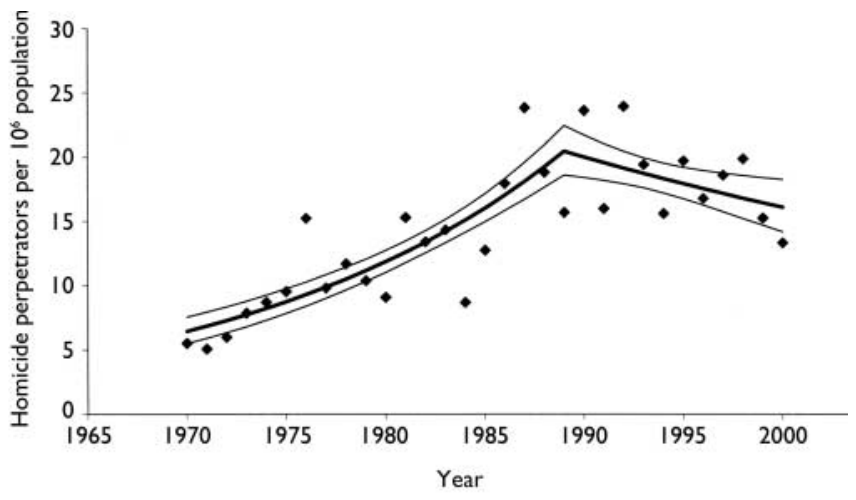

Fig. I Homicide perpetrators in New Zealand 1970-2000.

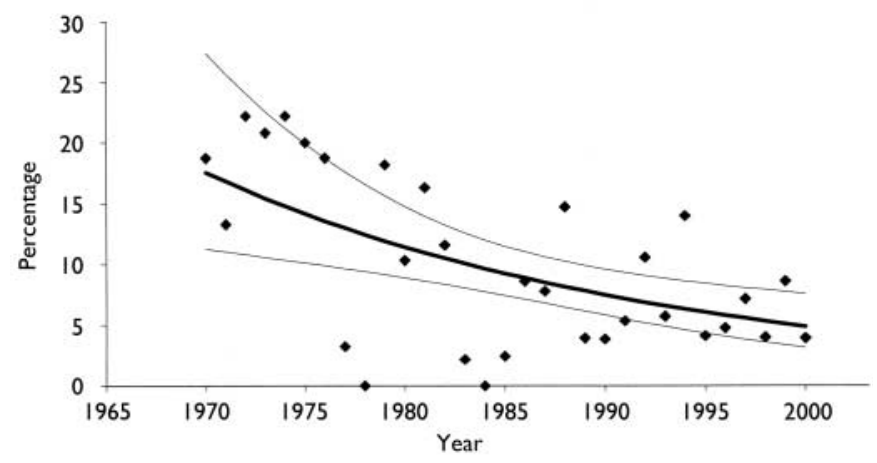

Fig. 2 Perpetrators of mentally abnormal homicides as a percentage of all homicides.

Table I Demographic characteristics of homicide offenders 1979-2000

\begin{tabular}{|c|c|c|c|c|c|}
\hline \multirow[t]{2}{*}{ Characteristics } & \multicolumn{2}{|c|}{$\begin{array}{c}\text { Mentally normal } \\
\text { offenders }(n=\mid 156)\end{array}$} & \multicolumn{2}{|c|}{$\begin{array}{l}\text { Mentally abnormal } \\
\text { offenders }(n=93)\end{array}$} & \multirow[t]{2}{*}{$P$} \\
\hline & $n$ & (\%) & $n$ & (\%) & \\
\hline \multicolumn{6}{|l|}{ Gender } \\
\hline Male & 1051 & (91) & 62 & (67) & >0.00 I \\
\hline Female & 105 & (9) & 31 & (33) & \\
\hline \multicolumn{6}{|l|}{ Age, years } \\
\hline $14-19$ & 225 & $(20)$ & 2 & (2) & $<0.001^{2}$ \\
\hline $20-29$ & 510 & $(45)$ & 41 & $(46)$ & \\
\hline $30-39$ & 259 & (23) & 23 & $(26)$ & \\
\hline $40-49$ & 94 & (8) & 13 & (I5) & \\
\hline 50-59 & 32 & (3) & 7 & (8) & \\
\hline $60+$ & 9 & (I) & 3 & (3) & \\
\hline Unknown & 27 & & 4 & & \\
\hline \multicolumn{6}{|l|}{ Ethnicity } \\
\hline NZ European & 461 & $(4 I)$ & 25 & (39) & $0.85^{3}$ \\
\hline Maori & 505 & $(45)$ & 27 & $(42)$ & \\
\hline Pacific peoples & 135 & $(12)$ & 10 & $(16)$ & \\
\hline Other & 34 & (3) & 2 & (3) & \\
\hline Unknown & 21 & & 29 & & \\
\hline
\end{tabular}

NZ, New Zealand.

I. Pearson $\chi^{2}=52.2$, d.f. $=1$.

2. Pearson $\chi^{2}=29.9$, d.f. $=5$.

3. Pearson $\chi^{2}=0.8 I$, d.f. $=3$. 
from 1970 to 2000 , and that this rate did not alter over time. As there was a substantial increase in the rates of homicide to 1990 and a much smaller decrease in the subsequent years to 2000 , the percentage of all homicides attributed by the courts to mental illness declined. Thus, people with mental illness contribute proportionately less to total homicide now than they did in 1970. This rate of mentally abnormal homicide is at the lower end of rates published internationally. Coid (1983) found that the rate varied between 0.8 and 2.2 per million per year. In more recent studies, Boscredon-Noe et al (1997) cited a rate in southern France that varied between 2.3 and 3.0 per million per year from 1838 to 1995. Erb et al (2001) found a rate of 1.1 in one part of Germany, rising to 2.5 in recent decades.

Studies have found percentages of total homicides perpetrated by people with serious mental illness varying between $1.6 \%$ in Ceylon and 53\% in north Sweden (Mouzos, 1999). The best-designed studies, in the UK (Taylor \& Gunn, 1999) and in Canada (Cote \& Hodgins, 1992), revealed percentages of $11 \%$ and $12.6 \%$ respectively. Coid's review found percentages ranging from $2.6 \%$ to $21.2 \%$ across 15 studies (Coid, 1983); Coid notes that the higher the homicide rate in a country, the lower the proportion committed by people who are mentally ill. Our finding of $8.7 \%$ is therefore in the mid-range of rates reported in international studies. Over the 30 years reviewed in our study, total homicide rates increased four-fold. Like Taylor \& Gunn (1999) we found a reduction in the contribution of mentally abnormal homicide to total homicide at a rate of $4.2 \%$ per year, while Taylor \& Gunn (1999) found a reduction of $3 \%$ per year. Despite this proportion being sensitive to changes in totalpopulation homicide trends, it is an important contextual finding when considering the proportion of all homicide in the community that can be attributed to serious mental illness.

Our finding of no alteration in the rate of mentally abnormal homicide since deinstitutionalisation is similar to other studies (Gabrielsen et al, 1992; Taylor \& Gunn, 1999; Erb et al, 2001), although Erb et al suggested that there might be a small time effect.

Our finding of more female offenders and older offenders in the mentally abnormal homicide group is entirely in keeping with prior comparative studies.

\section{CLINICAL IMPLICATIONS}

- Homicides by mentally ill persons have not increased as a population rate.

- People in a close personal relationship with the perpetrator are most at risk of being the victim.

- These findings are consistent with other homicide studies in Europe.

\section{LIMITATIONS}

- Legal definitions were used for identifying particular groups studied.

- The study drew on secondary data sources only, with significant missing demographic data.

- The contribution of mental illness to some homicides may not have been detected or accepted in the courts.

ALEXANDER I. F. SIMPSON, MBChB, BMedSci, FRANZCP, Academic Forensic Psychiatry Unit, Division of Psychiatry, Faculty of Medicine and Health Sciences, University of Auckland, and Auckland Regional Forensic Psychiatry Service; BRIAN McKENNA, RCpN, BA, MHSc (Hons), School of Nursing, Faculty of Medicine and Health Science, University of Auckland, and Auckland Regional Forensic Psychiatry Service; ANDREW MOSKOWITZ, PhD, Department of Psychology, University of Auckland; JEREMY SKIPWORTH, MBChB, MMedSc (Hons), FRANZCP, Wellington School of Medicine, University of Otago, and Central Regional Forensic Psychiatry Service, Capital and Coast District Health Board; JUSTIN BARRY-WALSH, MBChB, BMedSci, FRANZCP, Wellington School of Medicine, University of Otago, and Central Regional Forensic Psychiatry Service, Capital and Coast District Health Board, Wellington, New Zealand

Correspondence: Dr Sandy Simpson, Auckland Regional Forensic Psychiatry Service, Private Bag 19986, Avondale, Auckland, New Zealand. E-mail: sandy.simpson@waitematadhb.govt.nz

(First received II December 2003, final revision I June 2004, accepted 26 June 2004)

Mouzos (1999) found similar age and gender differences. In her Australian sample, those in the mentally normal homicide group were 5 years younger than those in the mentally abnormal group. She also found that $5.4 \%$ of the mentally abnormal group had an intellectual disability, whereas in our group it was $7 \%$. The finding that the victims of mentally abnormal homicide are predominantly people known to the perpetrator is also in keeping with the findings of Mouzos (1999) in Australia, Gottlieb et al (1987) in Denmark and in Nestor \& Haycock's case-control series in the USA (Nestor \& Haycock, 1997). In our series, victims of homicide by someone with a serious mental illness were very unlikely to be a stranger to the perpetrators: our finding was even lower than the $10.2 \%$ of the Australian series (Mouzos, 1999). Lack of prior contact with mental health services was evident in $29 \%$ of our mentally abnormal homicide sample, which is similar to the findings of Shaw et al (1999).

The use of legal criteria to define the mentally abnormal group, rather than a survey or case register design, has both advantages and disadvantages. We needed to use the legal definition to be able to study the time trends, as diagnostic and case register approaches were not possible prior to 1988. Second, the use of a legal definition allowed the establishment of a nexus between the serious mental illness and the offence, which a case register or survey design would not. Thus, the mentally abnormal homicide group in our study clearly had a contribution from the mental illness to the homicide, rather than it being a chance occurrence. The disadvantages are that the trends might reflect changes in legal policy or thresholds, and will miss those with a serious mental illness who 
were convicted of murder or manslaughter, in whom mental illness might have contributed to the offence but failed to reach the criteria of the insanity test or other legal thresholds. There are also cases of people who were found not guilty by reason of insanity who perhaps should have been convicted of murder, which may counterbalance this effect. Our experience in reviewing the files and from the involvement of members of the research team in many of these cases does not suggest any major drift in policy or interpretation of law, especially in the last 12 years of the study.

\section{Implications for service and public policy}

There is little support from these data for a policy of re-institutionalisation. Difficulties have been encountered in the provision of mental health care to people who may have comorbid substance use and lack the social support necessary for effective recovery from serious mental illness. The recent expansion in resources to community mental health care, introduction of recovery-based and family-friendly mental health policies, effective forensic mental health services, new and more effective antipsychotic medications, and community-based compulsory treatment may have an impact on rates of mentally abnormal homicide. Erb et al (2001) found the factors that were associated with mentally abnormal homicide in Germany to be a lack of proper services for high-risk patients and non-use of services by patients with first-episode illness. Thus, providing best-quality care to the small number of people with serious mental illness who may represent a significant risk to others is an important service priority.

\section{ACKNOWLEDGEMENTS}

This study was funded by a grant from the Mental Health Research and Development Strategy, on behalf of the Ministry of Health and Ministry of Justice. We thank Alistair Stewart of the Division of Public Health, University of Auckland for statistical advice, and Pauline Hinds, Charles Joe, Kaumatua Erika Edwards and Whaea Mihiarangi Karaka for consumer and Maori advice.

\section{REFERENCES}

American Psychiatric Association (1994) Diagnostic and Statistical Manual of Mental Disorders (4th edn) (DSM-IV). Washington, DC: APA.

Boscredon-Noe, J. P., Rozieres, J. L. \& Moron, P. (1997) Violences graves des malades mentaux en milieu familial. Annales Medicopsychologiques, I55, 552-556. Cited in Woodward, M., Nurtsten, J., Williams, P., et al (2000) Mental disorder and homicide: a review of epidemiological research. Epidemiologia e Psichiatria Sociale, 9, 171-189.

Coid, J. (1983) The epidemiology of abnormal homicide and murder followed by suicide. Psychological Medicine, 13, 855-860.

Cote, G. \& Hodgins, S. (1992) The prevalence of major mental disorders among homicide offenders. International Journal of Law and Psychiatry, 15, 89-99.

Erb, M., Hodgins, S., Freese, R., et al (200I) Homicide and schizophrenia: maybe treatment does have a preventive effect. Criminal Behaviour and Mental Health, II, 6-26.

Eronen, M., Hakola, P. \& Tiihonen, J. (1996) Mental disorders and homicidal behavior in Finland. Archives of General Psychiatry, 53, 497-50I.
Gabrielsen, G., Gottlieb, P. \& Kramp, P. (1992) Criminal homicide trends in Copenhagen. Studies on Crime and Crime Prevention, I, I06-114.

Gottlieb, P., Gabrielsen, G. \& Kramp, P. (1987) Psychotic homicides in Copenhagen from 1959 to 1983. Acta Psychiatrica Scandinavica, 76, 285-292.

Leong, G. B. \& Silva, J. A. (1995) A psychiatric-legal analysis of psychotic criminal defendants charged with murder. Journal of Forensic Sciences, 40, 445-448.

Mouzos, J. (1999) Mental Disorder and Homicide in Australia. Trends and Issues in Crime and Criminal Justice, no. 133. Canberra: Australian Institute of Criminology.

Mullen, P. E., Burgess, P., Wallace, C., et al (2000) Community care and criminal offending in schizophrenia. Lancet, 355, 614-617.

Nestor, P. G. \& Haycock, J. (1997) Not guilty by reason of insanity of murder: clinical and neuropsychological characteristics. Journal of the American Academy of Psychiatry and the Law, 25, 161-171.

Office of the Police Commissioner (2003) New Zealand Crime Statistics 2002. http: //www. police. govt.nz/service/statistics/2002/calendar/stats-national2002I23I.pdf

Shaw, J., Appleby, L., Amos, T., et al (1999) Mental disorder and clinical care in people convicted of homicide: national clinical survey. BM/, 318, 137-138.

Simpson, A. I. F., McKenna, B., Moskowitz, A., et al (2003) Myth and Reality: The Relationship Between Mental IIIness and Homicide in New Zealand. Auckland: Health Research Council of New Zealand. http: // www.hrc.govt.nz/assets/pdfs/Myth\&Reality.pdf

SPSS (2002) Statistical Package for the Social Sciences, version II. Chicago, IL: SPSS Inc.

Taylor, P. J. \& Gunn, J. (1999) Homicides by people with mental illness: myth and reality. British Journal of Psychiatry, 174, 9-14.

Wallace, C., Mullen, P. E. \& Burgess, P. (2004)

Criminal offending in schizophrenia over a 25 -year period marked by deinstitutionalization and increasing prevalence of comorbid substance use disorders. American Journal of Psychiatry, 161, 716-727. 